OPEN ACCESS

Edited by:

Kezhen Qi,

Shenyang Normal University, China

Reviewed by:

Yongsheng Yang,

Shenyang Normal University, China

Enesca loan Alexandru,

Transilvania University of

Braşov, Romania

${ }^{*}$ Correspondence:

Shreya Ghosh

shreyaghosh215@gmail.com

Specialty section: This article was submitted to

Nanoscience,

a section of the journal

Frontiers in Chemistry

Received: 15 April 2020

Accepted: 08 June 2020

Published: 11 August 2020

Citation:

Ghosh S, Chen Y, George A, Dutta M and Stroscio MA (2020) Fluorescence

Resonant Energy Transfer-Based Quantum Dot Sensor for the Detection of Calcium lons. Front. Chem. 8:594.

doi: 10.3389/fchem.2020.00594

\section{Fluorescence Resonant Energy Transfer-Based Quantum Dot Sensor for the Detection of Calcium lons}

\author{
Shreya Ghosh ${ }^{1 *}$, Yinghua Chen ${ }^{2}$, Anne George ${ }^{2}$, Mitra Dutta ${ }^{3,4}$ and Michael A. Stroscio ${ }^{3,4,5}$ \\ ${ }^{1}$ Micro and Nanotechnology Laboratory, University of Illinois at Urbana-Champaign, Urbana, IL, United States, ${ }^{2}$ Department \\ of Oral Biology, University of Illinois at Chicago, Chicago, IL, United States, ${ }^{3}$ Department of Electrical and Computer \\ Engineering, University of Illinois at Chicago, Chicago, IL, United States, ${ }^{4}$ Department of Physics, University of Illinois at \\ Chicago, Chicago, IL, United States, ${ }^{5}$ Department of Bioengineering, University of Illinois at Chicago, Chicago, IL, \\ United States
}

A simple optical aptasensor has been synthesized for the detection of calcium ions. This sensing approach employs a semiconductor quantum dot (QD)-gold nanoparticle as the donor-quencher pair and operates on the principle of fluorescence resonant energy transfer (FRET). On binding with calcium ions, the DNA aptamer undergoes a conformational change, which changes the distance between the quantum dot and the gold nanoparticle, conjugated on the $5^{\prime}$ terminal and $3^{\prime}$ terminal of the aptamer, respectively. This phenomenon results in the quenching of the quantum dot emission. In this sensor, a maximum quenching of $22.42 \pm 0.71 \%$ has been achieved at $35 \mathrm{nM}$ calcium ion concentration while the limit of detection has been determined to be 3.77 $\mathrm{pM}$. The sensor has been found to have high specificity for calcium ions in comparison to other metal ions like sodium, magnesium, and potassium. The molecular apta-beacons also demonstrated successful endocytosis and FRET-based calcium ion detection in osteocyte cells when conjugated with a cell-penetrating peptide (DSS).

Keywords: aptamer, biosensor, calcium detection, FRET, quantum dot, optical sensor

\section{INTRODUCTION}

Calcium ions $\left(\mathrm{Ca}^{2+}\right)$ are an essential component of the physiological system. They play a significant role as an intracellular messenger, which regulates several cellular functions like secretion, contraction, excitability, and gene expression (Russell, 2011). An increased $\mathrm{Ca}^{2+}$ release can contribute to diseases like HIV, schizophrenia, and Alzheimer's disease (Wojda et al., 2008). The review by Feske et al. throws light on the role of $\mathrm{Ca}^{2+}$ signaling in congenital immunodeficiency syndromes along with autoimmunity and inflammatory conditions (Feske, 2007). For instance, in systemic lupus erythematosus (SLE), it has been observed that signaling through the B-cell receptor in $\mathrm{B}$ cells is abnormal and results in increased $\mathrm{Ca}^{2+}$ signals. Chung et al. reported that with an elevation in the $\mathrm{Ca}^{2+}$ concentration, there was a greater risk of long-term mortality after an acute ischemic stroke (Chung et al., 2015). Hence, owing to the significance of this metal ion in the physiological system, the objective of this study is to design a sensor, which rapidly detects $\mathrm{Ca}^{2+}$. Asif et al. reported a zinc oxide nanorod-extended gate field-effect transistor (MOSFET), which detected $\mathrm{Ca}^{2+}$ linearly between $1 \mu \mathrm{M}$ and $1 \mathrm{mM}$ (Asif et al., 2009). Several analytical techniques for $\mathrm{Ca}^{2+}$ sensing have been published in literature. 
Ankireddy designed an optical sensor consisting of highly fluorescent ethylenediaminetetraacetic acid (EDTA)-CDs (ECDs) to detect $\mathrm{Ca}^{2+}$ in human serum with a detection limit of 77 pM (Ankireddy and Kim, 2018). Calsequestrin-functionalized gold nanoparticles were employed by Kim et al. to detect $\mathrm{Ca}^{2+}$ colorimetrically in human serum (Kim et al., 2009). Asadnia et al. used an AlGaN/GaN transistor functionalized with poly(vinylchloride) (PVC)-based membranes as a sensing platform for $\mathrm{Ca}^{2+}$ (Asadnia et al., 2017). Other methods include potentiometric detection (Ganjali et al., 2005; Singh and Mehtab, 2007), microfluidic chips (Caglar et al., 2006), and ion-selective electrodes (Schefer et al., 1986). Although in the last few years the development of aptamer-based sensors for various kinds of target detection has attracted huge interest, they have been hardly explored in the field of $\mathrm{Ca}^{2+}$ detection. Aptasensors utilize short single-stranded DNA/RNA oligonucleotides to bind to a specific target molecule. The binding affinity can be transduced using various methods and therefore can be employed as a primary sensing component in several types of sensors. In this manuscript, we have designed a DNA aptamer-based optical sensor for the detection of calcium ions. This sensor is based on the principle of FRET, which changes the photoluminescence (PL) intensity of the semiconductor quantum dot crystal depending on its distance with the gold nanoparticle quencher (Figure 1A).

The phenomenon of fluorescence resonance energy transfer (FRET) facilitates transfer of energy from a "donor" to an "acceptor." In the process of FRET, the efficiency is proportional to $1 /\left\{1+\left(d / d_{0}\right)^{6}\right\}$, where $d$ is the distance between the donor and the acceptor and $d_{o}$ has been determined to be approximately
$5 \mathrm{~nm}$ (Markvart, 2000; Yun et al., 2005; Shu et al., 2013). This distance-dependent behavior occurs due to dipole-dipole interactions between the donor and the acceptor. The effect of FRET is relatively strong when dis less than about $5 \mathrm{~nm}$ and starts getting weaker when $\mathrm{d}$ is greater than about $5 \mathrm{~nm}$. This study incorporates a quantum dot as the donor and a gold nanoparticle as the acceptor. Variation of distance between the QD and the nanoparticle quencher causes a transfer of energy from the QD to the nanoparticle. When $\mathrm{d}$ between $\mathrm{QD}$ and the nanoparticle acceptor is less than $5 \mathrm{~nm}$, there is less energy available in the QD to emit as photons because of a strong transfer of energy from it to the quencher. Consequently, the QD light emission decreases significantly. The sensor design involves the QD donor and the gold nanoparticle acceptor conjugated to opposite ends of a DNA aptamer, which functions as the primary sensing element here. This is because the aptamer has the ability to change its conformation on binding to the target analyte. As a result of the change in the conformational shape of the aptamer, there is a variation in $d$, which further causes a change in the intensity of the light emitted by the QD. Therefore, this change in QD emission can be considered as an indicator of $\mathrm{d}$ as well as the binding between the aptamer and the target. This phenomenon has been used as the principle of $\mathrm{Ca}^{2+}$ detection in this molecular beacon-based sensing platform.

In the recent years, quantum dots of various types of composition (Qi et al., 2016; Jia et al., 2020) have attracted huge attention because of their applicability in a wide variety of biomedical applications (Wegner et al., 2019; Song et al., 2020). We have successfully detected biomarker proteins like glycated albumin (Ghosh et al., 2017) and tumor necrosis factor-

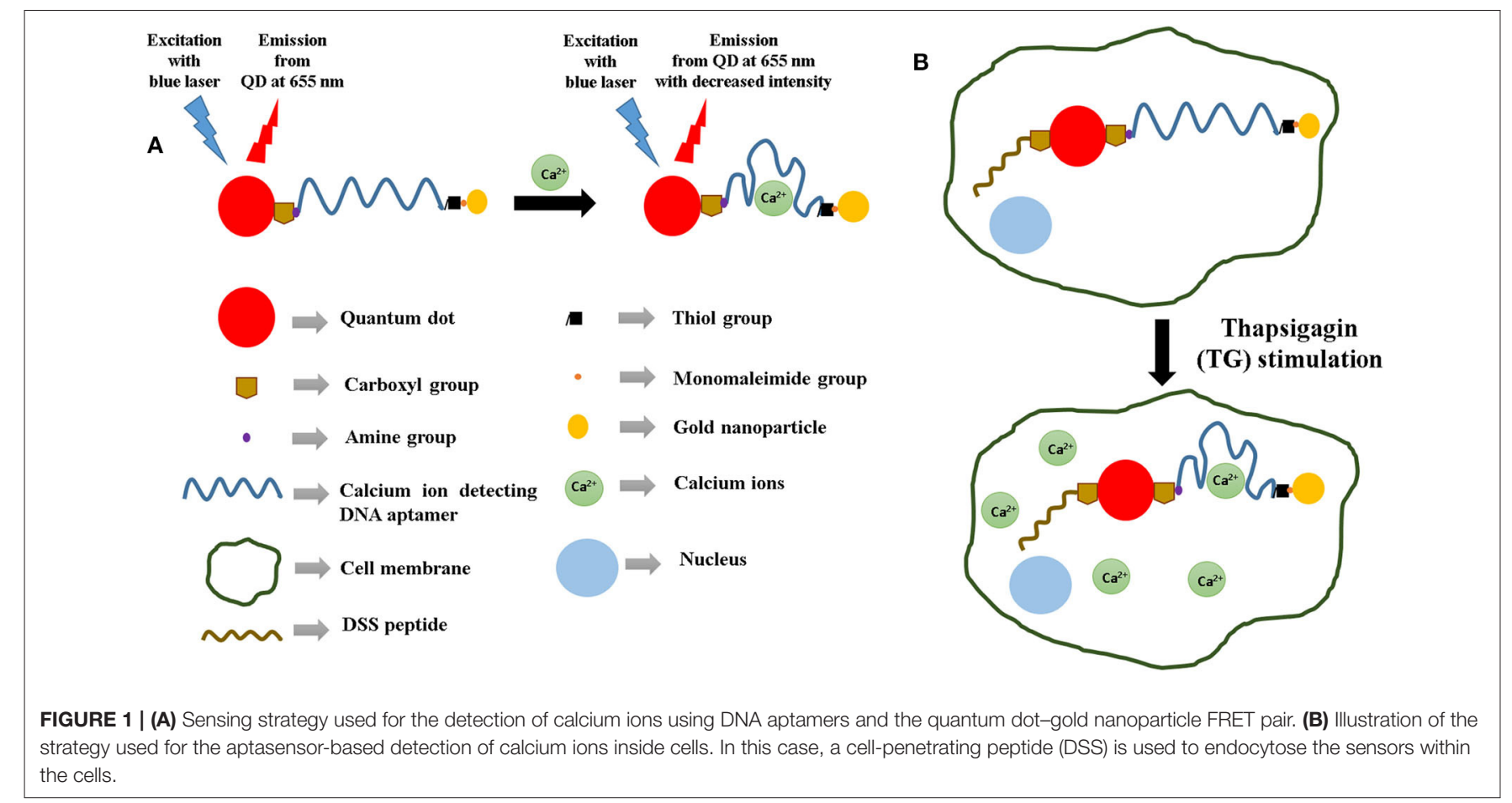


alpha (Ghosh et al., 2018) using this design strategy. Apart from biomarker proteins, our group has also used this sensing strategy to detect metal ions like potassium (Wu et al., 2011; Meshik et al., 2014), lead (Brenneman et al., 2013; Meshik et al., 2014), and mercury (Brenneman et al., 2010). The innovation of this study lies in the design of the sensor, which has a cell-penetrating peptide conjugated to the aptamer-based FRET sensor. Such a sensor for the detection of calcium ions has not been reported in literature previously. Therefore, this paper also investigates the response of a cell-penetrating peptide (DSS)-conjugated aptasensor inside a cellular environment and its effectiveness in detecting intracellular $\mathrm{Ca}^{2+}$ (Figure 1B). Such aptasensors have the potential of being incorporated in point-of-care setups for clinical applications.

\section{MATERIALS AND METHODS}

\section{Materials Used for Synthesis and Testing of Molecular Beacon}

The calcium-detecting DNA aptamer was purchased from Biosearch Technologies (Petaluma, CA). Calcium chloride dihydrate $\left(\mathrm{CaCl}_{2} \cdot 2 \mathrm{H}_{2} \mathrm{O}\right), 2 \mathrm{M}$ magnesium chloride $\left(\mathrm{MgCl}_{2}\right)$ solution, and $5 \mathrm{M}$ sodium chloride $(\mathrm{NaCl})$ solution were purchased from Sigma-Aldrich (St. Louis, MO) while $4.6 \mathrm{M}$ potassium chloride $(\mathrm{KCl})$ solution was obtained from Fischer Chemicals (Fairlawn, NJ). 1-Ethyl-3-(3-dimethylaminopropyl)carbodiimide (EDC) and tris(2-carboxyethyl)phosphine (TCEP) were purchased from Pierce Biotechnology (Rockford, IL). Monomaleimide-functionalized nanogold particles (diameter $=1.4 \mathrm{~nm}$ ) were obtained from Nanoprobes (Yaphank, NY). Carboxyl-coated CdSe/ZnS QDs e-flour ITK 655NC (diameter $=20 \mathrm{~nm}$ ) was obtained from Life Technologies (Carlsbad, CA). Nanosep molecular weight cutoff (MWCO) filters of 3 and $100 \mathrm{k}$ pore sizes were purchased from Pall Life Sciences (Ann Arbor, MI).

\section{Aptamer Structure and Preparation of Aptamer Stock Solution}

The calcium-detecting DNA aptamer consisted of 12 bases and had been modified with an amine group on the $5^{\prime}$ terminal and a thiol functional group on the $3^{\prime}$ terminal $\left(5^{\prime}\right.$ amino C6/GGGGTTTTGGGG/thiol C6 SS $3^{\prime}$ ). The aptamer was dissolved into $654 \mu \mathrm{l}$ of tris ethylenediamine tetraethyl acetate (EDTA) buffer to obtain $100 \mu \mathrm{M}$ aptamer stock solution in order to prevent cation-induced degradation.

\section{Preparation of Molecular Beacon}

The molecular beacon was synthesized based on the protocol reported by Ghosh et al. $(2017,2018)$. Briefly, $9 \mu$ of TCEP was added to $20 \mu \mathrm{l}$ of the $100 \mu \mathrm{M}$ calcium-detecting aptamer. The mixture was allowed to incubate for $30 \mathrm{~min}$ at room temperature so that the dithiol groups in the aptamer get reduced. One vial of gold nanoparticles $(6 \mathrm{nmol})$ was added to $100 \mathrm{ml}$ of deionized water to form a solution, which was further added to the aptamer-TCEP mixture (quencher: aptamer $=3: 1$ approximately). This mixture was then incubated for $2 \mathrm{~h}$ at room temperature, after which it was centrifuged [Fisher Scientific accuSpin Micro (Fisher Scientific, USA)] twice at 5,000 rpm for 15 min each using a $3 \mathrm{k}$ MWCO filter. This step ensured the removal of excess unbound gold nanoparticles from the mixture. The supernatant after each centrifugation was washed with $50 \mu \mathrm{l}$ of deionized water. $13 \mu \mathrm{l}$ of carboxylated CdSe/ZnS QDs $(0.1 \mathrm{nmol})$ was mixed with $87 \mu \mathrm{l}$ of $10 \mathrm{mM}$ borate buffer ( $\mathrm{pH}$ 7.4) to form a $100 \mu \mathrm{l}$ QD solution, which was further added to the filtered DNA aptamer/gold nanoparticle solution in the presence of $23 \mu \mathrm{l}$ of $4 \mu \mathrm{g} / \mu \mathrm{l}$ EDC/Sulfo-NHS solution. The resulting mixture was then allowed to shake gently for $2 \mathrm{~h}$ at room temperature, following which the samples were centrifuged five times at 7,000 rpm for $5 \mathrm{~min}$ each using a $100 \mathrm{k}$ MWCO filter in $50 \mathrm{mM}$ borate buffer ( $\mathrm{pH}$ 8.3). The supernatant left after each centrifugation was washed with $50 \mu \mathrm{l}$ of the $50 \mathrm{mM}$ borate buffer ( $\mathrm{pH} 8.3$ ). This resulted in the removal of unbound aptamers and EDC from the sensor solution.

\section{Preparation of DSS Peptide-Conjugated Molecular Beacons for Calcium ion Sensing}

$9 \mu \mathrm{l}$ of TCEP was added to $20 \mu \mathrm{l}$ of the $100 \mu \mathrm{M}$ calcium-detecting aptamer. The mixture was allowed to incubate for $30 \mathrm{~min}$ at room temperature so that the dithiol groups in the aptamer get reduced. One vial of gold nanoparticles $(6 \mathrm{nmol})$ was added to $100 \mathrm{ml}$ of deionized water to form a solution, which was further added to the aptamer-TCEP mixture (quencher: aptamer $=3: 1$ approximately). This mixture was then incubated for $2 \mathrm{~h}$ at room temperature, after which it was centrifuged (Fisher Scientific accuSpin Micro [Fisher Scientific, USA)] twice at 5,000 rpm for 15 min each using a $3 \mathrm{k}$ MWCO filter. The supernatant after each centrifugation was washed with $50 \mu \mathrm{l}$ of deionized water. $13 \mu \mathrm{l}$ of carboxylated CdSe/ZnS QDs $(0.1 \mathrm{nmol})$ was mixed with $87 \mu \mathrm{l}$ of $10 \mathrm{mM}$ borate buffer ( $\mathrm{pH}$ 7.4) to form a $100 \mu \mathrm{l}$ QD solution. A $10-\mathrm{mg} / \mathrm{ml}$ DSS peptide solution was prepared by adding $2.3 \mathrm{mg}$ of the DSS peptide to $230 \mu \mathrm{l}$ of deionized water. $30 \mu \mathrm{l}$ of $4 \mu \mathrm{g} / \mu \mathrm{l}$ EDC/Sulfo-NHS solution was added to a mixture of $100 \mu \mathrm{l}$ of the QD solution, $230 \mu \mathrm{l}$ of the DSS peptide, and the filtered calcium aptamer/gold nanoparticle solution in order to facilitate binding. Subsequently, this mixture was allowed to shake for $2 \mathrm{~h}$ at room temperature, following which the samples were centrifuged five times at 7,000 rpm for $5 \mathrm{~min}$ each using a $100 \mathrm{k}$ MWCO filter in $50 \mathrm{mM}$ borate buffer ( $\mathrm{pH}$ 8.3). The supernatant obtained after each centrifugation cycle was washed with $50 \mu \mathrm{l}$ of the $50 \mathrm{mM}$ borate buffer ( $\mathrm{pH} 8.3$ ).

\section{DNA Secondary Structure Determination}

The secondary structure of the calcium ion-detecting DNA aptamer was predicted using the M-fold web server (SantaLucia, 1998; Peyret, 2000; Zuker, 2003). The predicted secondary structures were compared at different temperatures and sodium ion $\left(\mathrm{Na}^{+}\right)$concentrations. The temperatures used are as follows: (1) $20^{\circ} \mathrm{C}$ : This has been considered as the room temperature and the temperature in which the optical characterization experiments were conducted (2) $37^{\circ} \mathrm{C}$ : This is the temperature under physiological conditions. There were three different ionic conditions considered: (1) $1.37 \mathrm{mM} \mathrm{Na}^{+}$, (2) $10 \mathrm{mM} \mathrm{Na}{ }^{+}$, and (3) $150 \mathrm{mM} \mathrm{Na}^{+}$. These sodium ion concentrations were chosen because the $\mathrm{Na}^{+}$concentration for this aptasensor is approximately $1.37 \mathrm{mM}$ while the concentration of $\mathrm{Na}^{+}$in a 
mammalian cell and blood is around 12 and $145 \mathrm{mM}$, respectively (Lodish et al., 2000).

\section{Sensitivity Determination of Sensor}

The $1 \mathrm{M} \mathrm{CaCl}_{2}$ stock solution was prepared by adding $1 \mathrm{~g} \mathrm{CaCl}_{2}$ to $10 \mathrm{ml}$ deionized water. This stock solution was serially diluted to obtain solutions having concentrations of $0.7 \mathrm{nM}, 3.5 \mathrm{nM}$, $7 \mathrm{nM}, 35 \mathrm{nM}, 0.7 \mu \mathrm{M}$, and $3.5 \mu \mathrm{M}$, respectively. These solutions were used as working solutions. $5 \mu$ l of these working solutions was added to $750 \mu \mathrm{l}$ of the sensor solution in the cuvette, which was then allowed to stand undisturbed for $5 \mathrm{~min}$. This time period ensured the binding of the calcium ion to the DNA aptamer in the sensor. The photoluminescence intensities were subsequently recorded using a USB4000 Ocean Optics (Dunedin, FL, USA) spectrophotometer with a continuous 375nm LED excitation.

\section{Specificity Determination of Sensor}

One-mM stock solutions of the control analytes $\left(\mathrm{NaCl}, \mathrm{MgCl}_{2}\right.$, and $\mathrm{KCl}$ ) were obtained by serially diluting the respective $5 \mathrm{M}$ $\mathrm{NaCl}, 2 \mathrm{M} \mathrm{MgCl}_{2}$, and $4.6 \mathrm{M} \mathrm{KCl}$ solutions. The respective stock solutions were then serially diluted to obtain $1 \mu \mathrm{M}$ and $100 \mu \mathrm{M}$ working solutions. These working solutions were added to the sensor solution in such a way that the final concentration of the

TABLE 1 | Gibbs-free energy values of the $\mathrm{Ca}^{2+}$-detecting DNA aptamer under various $\mathrm{Na}^{+}$concentrations and temperature conditions.

\begin{tabular}{lccc}
\hline Serial number & \multicolumn{2}{c}{ Parameters } & \multirow{\Delta}{*}{$\mathbf{G}(\mathbf{k c a l} / \mathbf{m o l})$} \\
\cline { 2 - 3 } & Temperature $\left({ }^{\circ} \mathbf{C}\right)$ & $\mathbf{N a}^{+}$concentration $(\mathbf{m M})$ & \\
\hline 1. & 20 & 1.37 & 2.71 \\
2. & 37 & 1.37 & 2.85 \\
3. & 20 & 10 & 2.71 \\
4. & 37 & 10 & 2.85 \\
5. & 20 & 150 & 2.61 \\
6. & 37 & 150 & 2.76
\end{tabular}

control analytes were $660 \mathrm{pM}, 7 \mathrm{nM}, 600 \mathrm{nM}$, and $7 \mu \mathrm{M}$. The PL spectra corresponding to the controls were recorded after $5 \mu \mathrm{l}$ of the control ion was added to $750 \mu$ of the sensor solution and allowed to stand disturbed for $5 \mathrm{~min}$.

\section{FRET Determination in an Intracellular Environment}

Mouse pre-osteocyte cells (MC3T3 E1-ATCC, Manassas, VA) were cultured in $\alpha$-MEM (Corning Inc., Corning, NY) with 10\% FBS (Thermo Fisher Scientific, Waltham, MA) and 1\% antibiotic-antimycotic $\left(100 \times\right.$, Life Technologies) at $37^{\circ} \mathrm{C}$ in a humidified incubator with $5 \% \mathrm{CO}_{2}$. The 300,000 cells were seeded on a $\varphi 25$-mm cover glass in a well of a 6 -well culture plate. The next day, the DSS-conjugated molecular beacons $(0.1 \mathrm{mg} / \mathrm{ml})$ were added. After $1 \mathrm{~h}$, the cells were washed with pre-warmed PBS without calcium and magnesium three times to remove un-incorporated/free molecular beacons. Then, thapsigargin (TG-final concentration at $1 \mu \mathrm{M}$ ) [MilliporeSigma, Burlington, MA)] in PBS without calcium and magnesium was added to trigger the calcium release from endoplasmic reticulum storage. At the indicated time point, formaldehyde solution (37\%) (Thermo Fisher Scientific, Waltham, MA) was added at $1 / 10$ of TG solution volume $(20 \mu \mathrm{L}$ to $200 \mu \mathrm{L})$ to stop the reaction and fix cells for $1 \mathrm{~h}$ at room temperature. After washing with PBS for 3 times, the cover glass was mounted on a glass slide with a mounting agent with DAPI (Vector Lab, Burlingame, CA). The fluorescence signals from the molecular beacons were observed with a Zeiss LSM 710 Confocal Microscope in Research Resources Center of University of Illinois at Chicago.

\section{RESULTS AND DISCUSSION Aptamer Structure}

The secondary structure of the DNA aptamer was found to be similar under all conditions mentioned in Figures 2A-F. As predicted by the $\mathrm{M}$-fold web server, the secondary structure had a characteristic external loop and a hairpin loop. The external

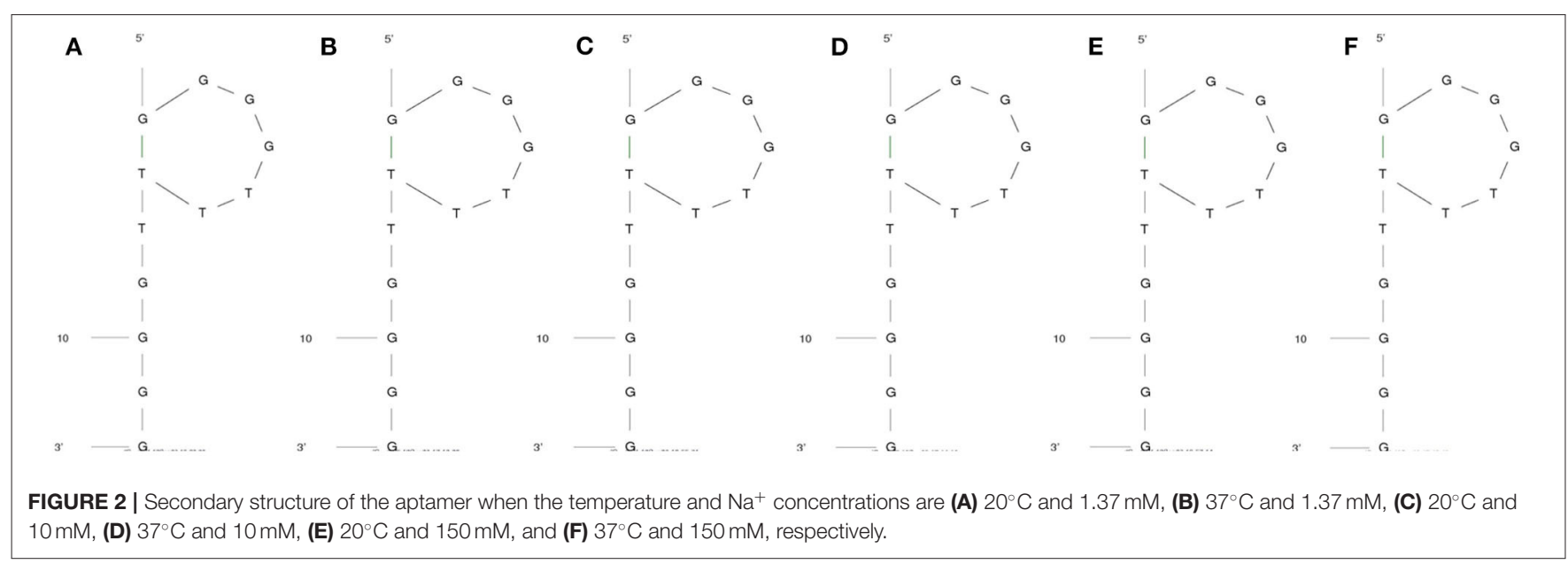



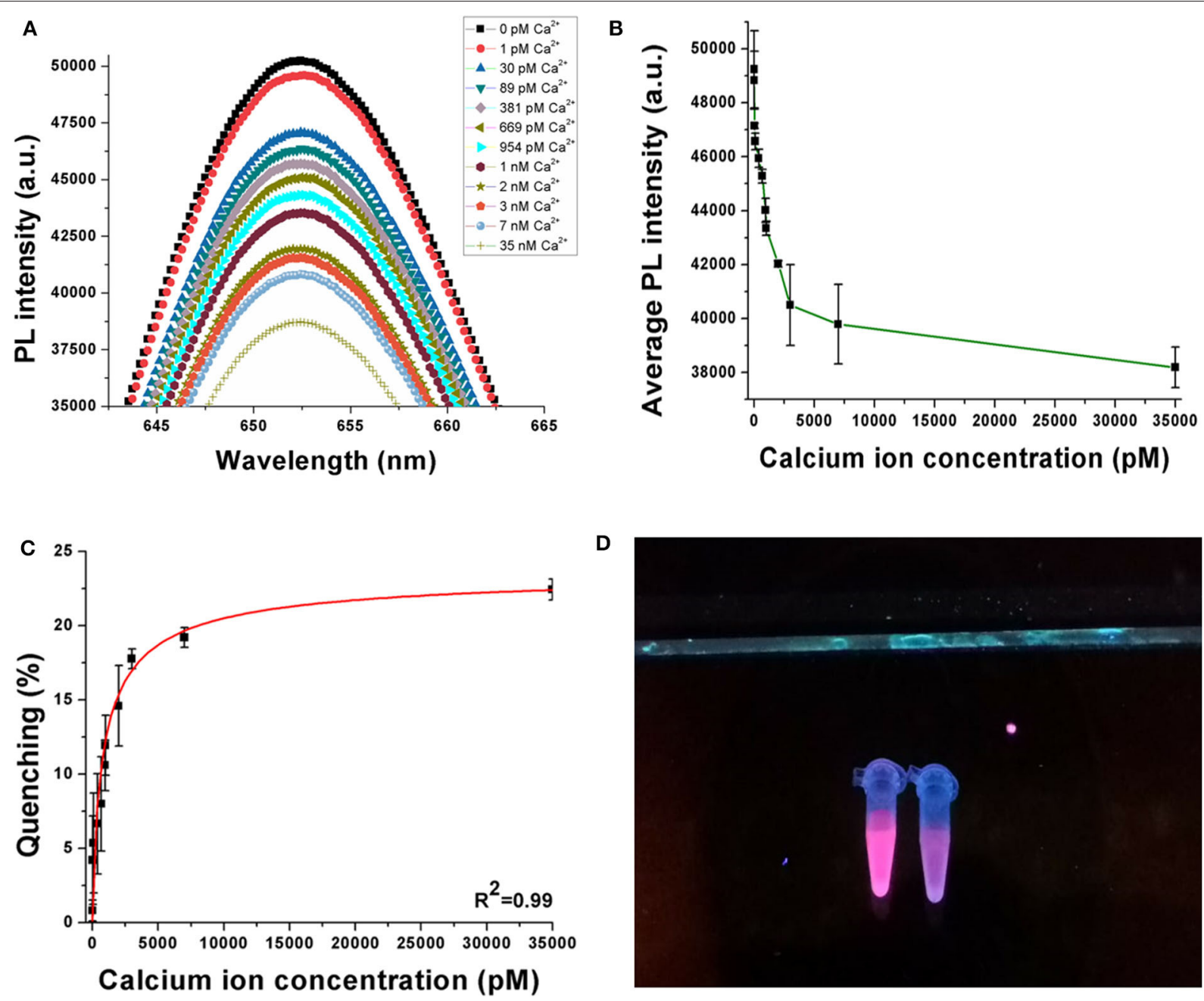

FIGURE 3 | (A) Decrease in PL intensity with increase in $\mathrm{Ca}^{2+}$ concentration. (B) Average PL intensity curve of the sensor when experiments are repeated with multiple samples. (C) Quenching behavior of the sensor when the concentration of $\mathrm{Ca}^{2+}$ is increased up to $35 \mathrm{nM}$. (D) Visual illustration of quenching phenomena in the sensor on addition of target ion. Experiments have been conducted in quintuplicates $(n=5)$.

loop was composed of 5 single-strand bases along with 1 closing helix. On the other hand, the hairpin loop had a closing pair at $\mathrm{G}^{1}-\mathrm{T}^{7}$. As shown in Table 1, Gibb's free energy was observed to increase with an increase in temperature while no such pattern was observed for the sodium ion concentration. The aptamer was chosen from the work reported by Miyoshi et al. (2003). They determined that the DNA aptamer underwent a structural transition from antiparallel to parallel G-quadruplex in the presence of $\mathrm{Ca}^{2+}$. This characteristic was utilized to induce FRET in the proposed sensor here.

\section{Sensitivity Determination of Sensor}

A decrease in photoluminescence intensity was observed with an increase in the concentration of the calcium ions. This phenomenon is shown in Figure 3A, where the PL spectra indicate a decrease when $\mathrm{Ca}^{2+}$ is progressively added between $0 \mathrm{pM}$ and $35 \mathrm{nM}$. A consistent repetition of this behavior is observed in Figure 3B when the experiments are repeated in quintuplicates $(n=5)$, where the average PL intensity decreases with an increase in the target ion concentration. Figure 3C shows the quenching behavior of the sensor samples. Quenching (\%) has been calculated using Equation (1), where $\mathrm{I}_{\text {blank }}$ is the peak photoluminescence intensity before the addition of target, $\mathrm{I}_{\mathrm{Ca}}$ is the peak photoluminescence intensity after the addition of $\mathrm{Ca}^{2+}$, and quenching (\%) is the quenching efficiency of the sensor. The quenching efficiency is an indicator of the occurrence of FRET in the sensor while detecting the target analyte (Held, 2005).

$$
\text { Quenching }(\%)=\frac{\left(I_{\text {blank }}-I_{C a}\right)}{I_{C a}} \times 100
$$

According to Figure 3C, the sensor achieves average quenching efficiencies of $4.2 \pm 2.97 \%$ and $22.42 \pm 0.71 \%$ at $30 \mathrm{pM}$ and $35 \mathrm{nM} \mathrm{Ca}^{2+}$ concentrations, respectively. This behavior can be 
TABLE 2 | Comparative summary of various sensing platforms reported in literature for calcium ion detection.

\begin{tabular}{|c|c|c|c|}
\hline Sensing element & Sensor type & $\begin{array}{l}\text { Limit of } \\
\text { detection }\end{array}$ & References \\
\hline Calmodulin (CaM) & Fiber-optic sensor & $5 \times 10^{-8} \mathrm{M}$ & Blair et al., 1994 \\
\hline Carboxylic polyether antibiotic A23187 & Fiber-optic sensor & $1 \times 10^{-7} \mathrm{M}$ & Suzuki et al., 1989 \\
\hline Ionophore $\mathrm{N}, \mathrm{N}, \mathrm{N}^{\prime}, \mathrm{N}^{\prime}$-tetracyclohexyl-3-oxapentanediamide & $\begin{array}{l}\text { Calcium-selective } \\
\text { electrode }\end{array}$ & $100 \mathrm{pM}$ & Schefer et al., 1986 \\
\hline $\begin{array}{l}\text { Sensing membrane consisting of modified merocyanine photoacid } \\
\text { polymer and a calcium ionophore in plasticized poly(vinyl chloride) }\end{array}$ & Optical sensor & $5 \times 10^{-4} \mathrm{M}$ & Johns et al., 2014 \\
\hline $\mathrm{NiCO}_{2} \mathrm{O}_{4}$ nanostructures on 3-dimensional graphene foam & $\begin{array}{l}\text { Electrochemical } \\
\text { sensor }\end{array}$ & $4.45 \mu \mathrm{M}$ & Wu et al., 2015 \\
\hline$\alpha$-Furildioxime ionophore & Potentiometric sensor & $1.25 \times 10^{-7} \mathrm{M}$ & $\begin{array}{l}\text { Singh and Mehtab, } \\
2007\end{array}$ \\
\hline $\begin{array}{l}\text { Arsenazo III (1,8-dihydroxynaphthalene-3,6-disulfonic } \\
\text { acid-2,7-bis[(azo-2)-phenyl arsenic acid]) }\end{array}$ & $\begin{array}{l}\text { Microfluidic fiber-optic } \\
\text { sensor }\end{array}$ & $2.68 \times 10^{-5} \mathrm{M}$ & Caglar et al., 2006 \\
\hline 2-[(2-Hydroxyphenyl)imino]-1,2-diphenylethanone (HD) & Potentiometric sensor & $8.0 \times 10^{-7} \mathrm{M}$ & Ganjali et al., 2005 \\
\hline Ethylenediaminetetraacetic acid (EDTA)-carbon dots & Optical sensor & $77 \mathrm{pM}$ & $\begin{array}{l}\text { Ankireddy and Kim, } \\
2018\end{array}$ \\
\hline Hexametaphosphate-capped CdS QDs & Optical sensor & $4 \mu \mathrm{M}$ & Liu et al., 2016 \\
\hline $\begin{array}{l}4,4^{\prime}, 4^{\prime \prime}, 4^{\prime \prime \prime}-((3,6-\text { Dicyanobenzene-1,2,4,5- } \\
\text { tetrayl)tetrakis(sulfanediyl))tetra-benzoic } \\
\text { acid }\end{array}$ & Optical sensor & $0.6 \mu \mathrm{M}$ & Chen et al., 2019 \\
\hline DNA aptamer & Optical sensor & $3.77 \mathrm{pM}$ & This work \\
\hline
\end{tabular}
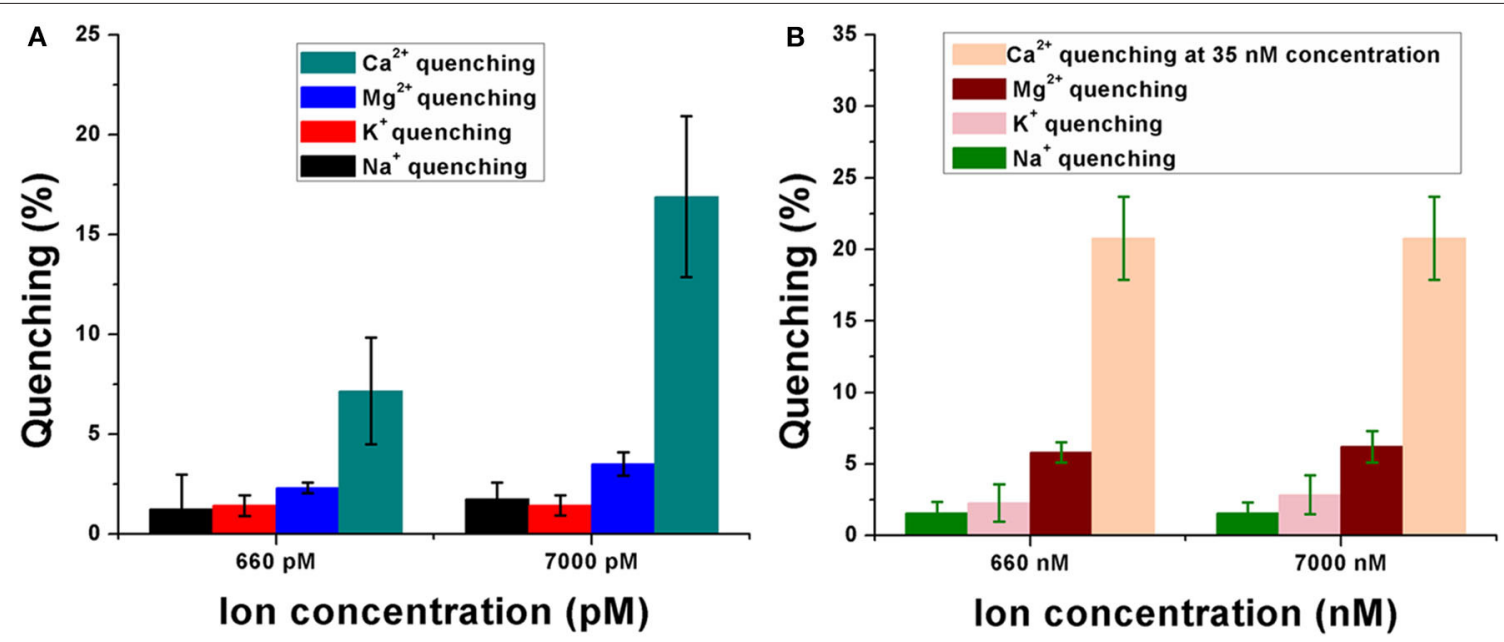

FIGURE 4 | Response of the calcium ion-detecting nanosensor when tested with control ions like sodium ( $\left.\mathrm{Na}^{+}\right)$, potassium $\left(\mathrm{K}^{+}\right)$, and magnesium (Mg $\left.{ }^{2+}\right)$. Quenching efficiencies of the target ion have been compared with that of the control ions in the pM concentration range (A) as well as in the $\mathrm{nM}$ range (B). Experiments have been conducted in quintuplicates $(n=5)$.

attributed to the phenomenon of FRET, where the DNA aptamer binds to the target analyte and changes its conformation, because of which the donor (QD) and the quencher (gold nanoparticles) are driven closer to each other. Consequently, owing to a dipole-dipole interaction between the FRET pair, there is an intersystem transfer of energy from the donor to the quencher. This reduces the resulting emission from the QDs, causing a decrease in PL intensity. As the concentration of the target ion is increased, a greater number of DNA aptamers bind to them and hence a higher number of QDs participate in FRET. In this case, the DNA aptamer has been reported to have an antiparallel G-quadruplex structure initially. Addition of $\mathrm{Ca}^{2+}$ induces the formation of a parallel G-quadruplex structure and finally to a G-wire structure. The parallel G-quadruplex has been found to be unstable, and hence, the aptamer rapidly transitions to the G-wire structure. The visual illustration shown in Figure 3D shows reduced fluorescence emission from the sample on the right compared to that on the left because the latter has no target analyte added to it while the former has $100 \mathrm{nM} \mathrm{Ca}^{2+}$ added. This further establishes the successful occurrence of FRET in the sensor on the addition of the target ion. 


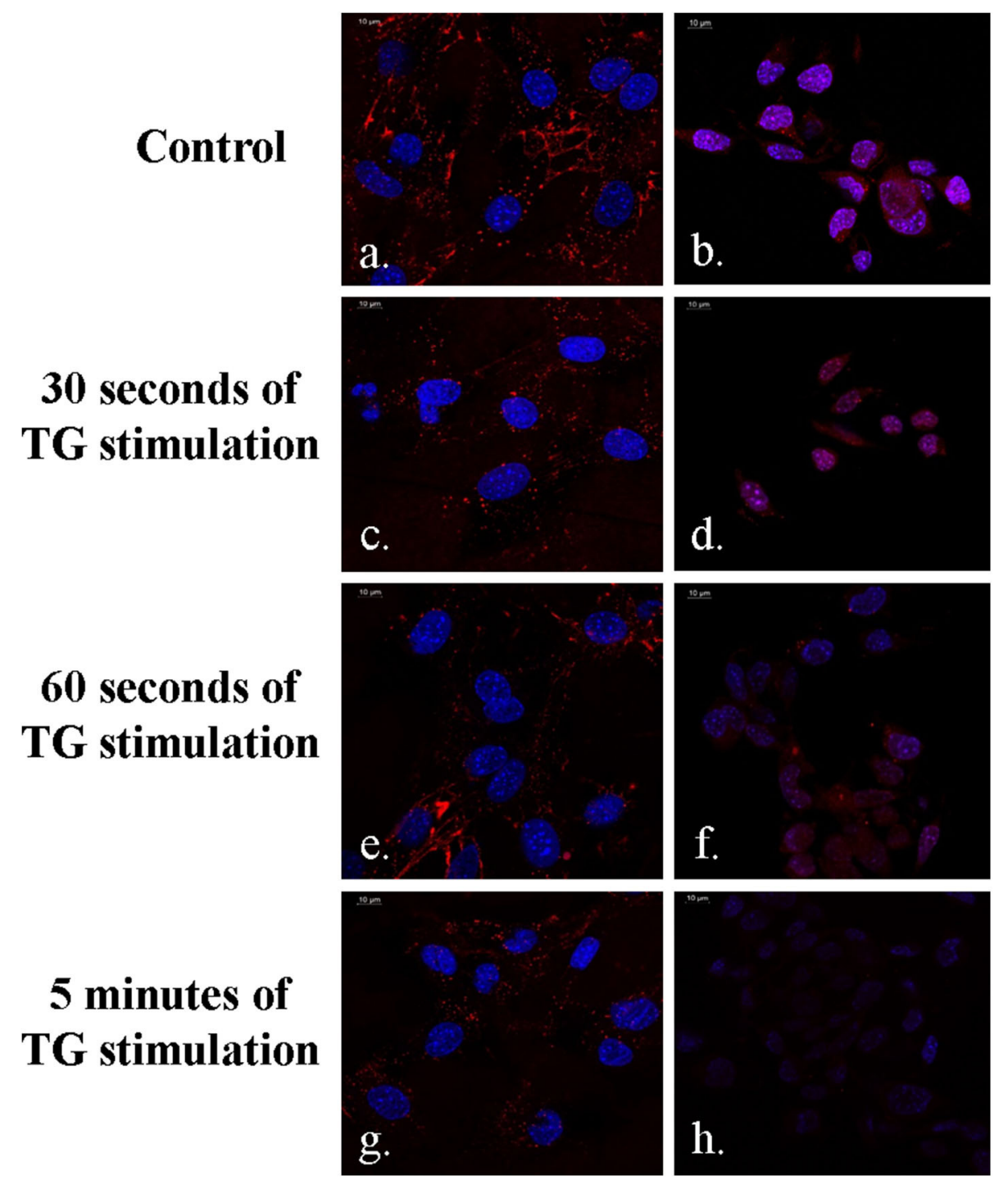

FIGURE 5 | Demonstration of FRET in MC3T3 cells in the presence of the DSS conjugated aptasensors (a-h). Fluorescence emission is minimum at 5 min of TG stimulation (g,h).

According to Figure 3C, the quenching behavior of the nanosensor follows the Hill chemical kinetics. In the Hill formalism, the quenching efficiency can be expressed as:

$$
\text { Quenching }=23.765 \times \frac{x^{0.765}}{\left(906.703^{0.765}+x^{0.765}\right)}
$$

Based on the definition of Hill's equation, 906.703 pM refers to the concentration at which half of the receptors are occupied by the target. The Hill coefficient of 0.765 is the slope of the Hill curve and also refers to negative cooperativity with respect to substrate binding. Also, from the equation theory, the average binding constant $\left(\mathrm{K}_{\mathrm{D}}\right)$ can be estimated as $183 \mathrm{pM}$.

$$
L O D=\frac{3 \times S D_{0}}{\text { Sensitivity }_{C a}}
$$

From the results obtained in Equation (3), where the $\mathrm{SD}_{0}$ is the normalized standard deviation of the blank sensor sample while Sensitivity $\mathrm{Ca}$ is the slope of the quenching curve (Figure 3C), the limit of detection (LOD) was calculated to be $3.77 \mathrm{pM}$ or 0.55 $\mathrm{pg} / \mathrm{ml}$ (assuming molecular weight of the $\mathrm{CaCl}_{2} \cdot 2 \mathrm{H}_{2} \mathrm{O}=147$ $\mathrm{g} / \mathrm{mol}$ ). The LOD obtained from this sensor has been compared with several other sensing platforms for $\mathrm{Ca}^{2+}$ in Table 2.

\section{Specificity Determination of Sensor}

The sensor was observed to have significant selectivity toward $\mathrm{Ca}^{2+}$ when compared to the control metal ions like $\mathrm{Na}^{+}$, $\mathrm{Mg}^{2+}$, and $\mathrm{K}^{+}$. These cations were specifically chosen because of their importance and abundance in the physiological system. Figure 4 shows the quenching behavior of the control ions in the picomolar $(\mathrm{pM})$ and nanomolar $(\mathrm{nM})$ concentration range. 

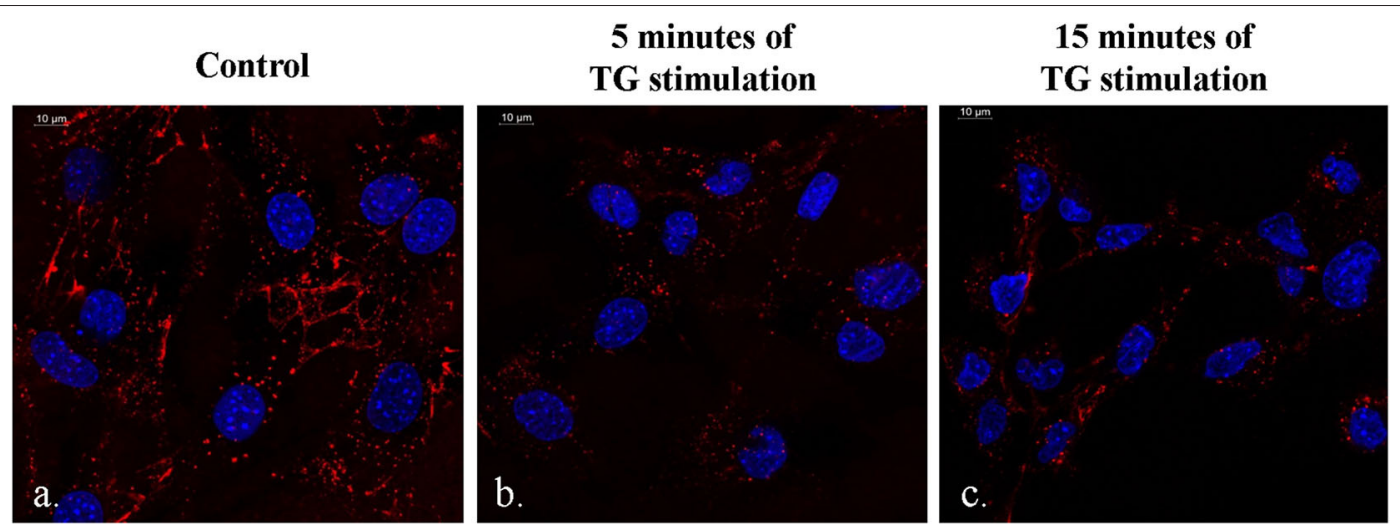

FIGURE 6 | Difference in the quantum dot emission from the DSS-conjugated molecular beacon in the presence of no TG stimulation (a), 5 min of TG stimulation (b), and 15 minutes of TG stimulation (c).

In Figure 4A, the quenching efficiencies have been compared between all the four ions while keeping their concentrations the same $(660 \mathrm{pM}$ and $7 \mathrm{nM}) . \mathrm{Ca}^{2+}$ was shown to have a significantly high quenching efficiency compared to $\mathrm{Na}^{+}, \mathrm{Mg}^{2+}$, and $\mathrm{K}^{+}$at both $660 \mathrm{pM}$ and $7 \mathrm{nM}$ concentrations, respectively (Figure 4B), indicating a high selectivity of the sensor toward calcium in the $\mathrm{pM}$ concentration range. A similar response was observed even when the concentration of the control ions is much higher $(660 \mathrm{nM}$ and $7 \mu \mathrm{M})$ in the sensor solution. Their quenching efficiencies were significantly lower than that of $\mathrm{Ca}^{2+}$ at $35 \mathrm{nM}$ concentration in the sensor. This further established the specificity of the aptasensor toward $\mathrm{Ca}^{2+}$.

\section{FRET Determination in an Intracellular Environment}

The DSS peptide is a cell-penetrating peptide, which is composed of amino acids like aspartic acid and serine. It allows successful endocytosis of the DNA aptamer-based molecular beacons, and this has been shown in Figures $\mathbf{5 a}-\mathbf{h}$, which clearly indicates the red emission from the $655 \mathrm{~nm}$ QDs in the DSS-conjugated molecular beacons. A higher-intensity QD emission from the MC3T3 cells was observed in Figures 5a,b in the absence of TG stimulation. This sample has been indicated in the figure as control. TG stimulation increases intracellular calcium release, during which a greater number of aptasensors bind to the higher concentration of $\mathrm{Ca}^{2+}$, causing greater reduction in the fluorescence emission. As can be seen in Figures $\mathbf{5} \mathbf{c}-\mathbf{h}$, with an increase in the duration of TG stimulation, there was an elevation in the concentration of intracellular $\mathrm{Ca}^{2+}$. This decreased the fluorescence emission from the QDs with the progression of time and resulted in successful quenching in the presence of the target ion.

It was observed that there was a slight increase in the QD emission from the DSS-conjugated molecular beacon when the duration of TG stimulation reached $15 \mathrm{~min}$ (Figures 6a-c). This phenomenon could be attributed to the structure of the DNA aptamer, which reorganizes itself to a G-wire formation. During this process, there is a possibility that the donor-quencher pair is driven away, causing a slight decrease in quenching. However, the difference in QD emission is not very high between 5 and 15 min (Figures 6b,c). Additionally, the phenomenon of FRET is still evident between the control sample and the sample with 15 min of TG stimulation (Figures 6a,c).

\section{CONCLUSION}

This study reports a simple DNA aptamer-based optical sensor, which detects $\mathrm{Ca}^{2+}$ between 0 pM and $35 \mathrm{nM}$. It employs a DNA aptamer as the primary $\mathrm{Ca}^{2+}$ sensing element and operates on the principle of FRET. It has the ability to detect the target ion up to a lower limit of $3.77 \mathrm{pM}$. Primary advantages of this sensor lie in its ability to successfully detect $\mathrm{Ca}^{2+}$ in an intracellular environment when used in conjunction with a cell-penetrating peptide (DSS). Additionally, it has very low sample requirement $(5 \mu \mathrm{l})$ and is quite flexible, i.e., the same sensing strategy can be used to detect other analytes by replacing the sensing element with a DNA aptamer specific to the analyte.

\section{DATA AVAILABILITY STATEMENT}

The original contributions presented in the study are included in the article/supplementary materials, further inquiries can be directed to the corresponding author/s.

\section{AUTHOR CONTRIBUTIONS}

MS and MD conceived and advised on the overall project idea. AG conceived the cell culture experiments. SG and YC performed the experiments and wrote the manuscript. All authors read and edited the manuscript.

\section{FUNDING}

This work was supported, in part, by the Army Research Office (subcontract FPO67468-01-PR to W911NF-18-1-0042) and the National Institutes of Health grant DE028531 (AG). 


\section{REFERENCES}

Ankireddy, S.R., and Kim, J. (2018). Chemical highly selective and sensitive detection of calcium (II) ions in human serum using novel fluorescent carbon dots. Sensor. Actuat. B-Chem. 255, 3425-3433. doi: 10.1016/j.snb.2017.09.172

Asadnia, M., Myers, M., Umana-membreno, G. A., Sanders, T. M., Mishra, U. K., Nener, B. D., et al. (2017). Analytica chimica Acta Ca 2 p detection utilising AlGaN/GaN transistors with ion-selective polymer membranes, Anal. Chim. Acta. 987, 105-110. doi: 10.1016/j.aca.2017.07.066

Asif, M.H., Nur, O., Willander, M., and Danielsson, B. (2009). Selective calcium ion detection with functionalized $\mathrm{ZnO}$ nanorods-extended gate MOSFET. Biosens. Bioelectron. 24, 3379-3382. doi: 10.1016/j.bios.2009.04.011

Blair, T.L., Yang, S., Smith-palmer, T., and Bachas, L.G. (1994). Fiber optic sensor for $\mathrm{Ca}^{2+}$ based on an induced change in the conformation of the protein calmodulin. Anal. Chem. 66, 300-302. doi: 10.1021/ac00074a019

Brenneman, K.L., Poduri, S., Stroscio, M.A., and Dutta, M. (2013). Optical detection of lead (II) ions using DNA-based nanosensor. IEEE Sens. J. 13, 1783-1786. doi: 10.1109/JSEN.2013.2241757

Brenneman, K.L., Sen, B., Stroscio, M.A., and Dutta, M. (2010). Aptamer-based optical bionano sensor for mercury (II) ions. Nanotechnol. Mater. Devices Conf. (NMDC), IEEE 2010, 221-224. doi: 10.1109/NMDC.2010.5652331

Caglar, P., Tuncel, S. A., Malcik, N., Landers, J. P., and Ferrance, J. P. (2006). A microchip sensor for calcium determination. Anal. Bioanal. Chem. 386, 1303-1312. doi: 10.1007/s00216-006-0776-8

Chen, G., Zhou, Z., and Feng, H. (2019). An aggregation-induced phosphorescence probe for calcium ion-specific detection and live-cell imaging in Arabidopsis thaliana. Chem. Commun. 55, 4841-4844. doi: 10.1039/C9CC01580A

Chung, J., Ryu, W., Kim, J., and Yoon, B. (2015). Elevated calcium after acute ischemic stroke : association with a poor short-term outcome and long-term mortality. J. Stroke 17, 54-59. doi: 10.5853/jos.2015.17.1.54

Feske, S. (2007). Calcium signalling in lymphocyte activation and disease. Nat. Rev. Immunol. 7, 690-702. doi: 10.1038/nri2152

Ganjali, M. R., Zamani, H. A., Norouzi, P., Adib, M., and Accedy, M. (2005). Novel calcium sensor based on [2-(2-Hydroxyphenyl)aimino]-1, 2diphenylethanone. Acta Chim. Slov. 52, 309-316. Available online at: http:// acta-arhiv.chem-soc.si/52/52-3-309.pdf

Ghosh, S., Datta, D., Cheema, M., Dutta, M., and Stroscio, M. A. (2017). Aptasensor based optical detection of glycated albumin for diabetes mellitus diagnosis. Nanotechnology 28:aa893a. doi: 10.1088/1361-6528/aa893a

Ghosh, S., Datta, D., Chaudhry, S., Dutta, M., and Stroscio, M. A. (2018). Rapid detection of tumor necrosis factor-alpha using quantum dot based optical aptasensor. IEEE Trans. Nanobiosci. 17, 417-423. doi: 10.1109/TNB.2018.2852261

Held, P. (2005). An Introduction to Fluorescence Resonance Energy Transfer (FRET) Technology and its Application in Bioscience, BioTek. Available online at: https://www.biotek.com/resources/white-papers/an-introduction-tofluorescence-resonance-energy-transfer-fret-technology-and-its-applicationin-bioscience/

Jia, J., Sun, Y., Zhang, Y., Liu, Q., Cao, J., Huang, G., et al. (2020). Facile and efficient fabrication of bandgap tunable carbon quantum dots derived from anthracite and their photoluminescence properties. Front. Chem. 8:123. doi: $10.3389 /$ fchem. 2020.00123

Johns, V. K., Patel, P. K., Hassett, S., Calvo-marzal, P., Qin, Y., and Chumbimunitorres, K. Y. (2014). Visible light activated ion sensing using a photoacid polymer for calcium detection. Anal. Chem. 86, 23-26. doi: 10.1021/ac500956j

Kim, S., Park, J. W., Kim, D., Kim, D., Lee, I., and Jon, S. (2009). Bioinspired colorimetric detection of calcium (II) ions in serum using calsequestrinfunctionalized gold nanoparticles. Angew. Chem. Int. Ed. 48, 4138-4141. doi: 10.1002 /anie.200900071

Liu, S., Wang, H., Cheng, Z., and Liu, H. (2016). Hexametaphosphate-capped quantum dots as fluorescent probes for detection of calcium ion and fluoride. Sensor. Actuat. B-Chem. 232, 306-312. doi: 10.1016/j.snb.2016.03.077

Lodish, H., Berk, A., Zipursky, S. L., Matsudaira, P., Baltimore, D., and Darnell, J. (2000). Intracellular Ion Environment and Membrane Electric Potential. Mol. Cell Biol. 4th Edn. New York, NY: WH Freeman.

Markvart, T. (2000). Light harvesting for quantum solar energy conversion. Prog. Quantum. Electron. 24, 107-186. doi: 10.1016/S0079-6727(00)00003-3
Meshik, X., Xu, K., Dutta, M., and Stroscio, M. A. (2014). Optical detection of lead and potassium ions using a quantum-dot-based aptamer nanosensor. IEEE Trans. Nanobiosci. 13, 161-164. doi: 10.1109/TNB.2014. 2317315

Miyoshi, D., Nakao, A., and Sugimoto, N. (2003). Structural transition from antiparallel to parallel G-quadruplex of d (G $4 \mathrm{~T} 4 \mathrm{G} 4)$ induced by $\mathrm{Ca}^{2+}$. Nucleic Acids Res. 31, 8-9. doi: 10.1093/nar/gkg211

Peyret, N. (2000). Prediction of Nucleic Acid Hybridization: Parameters and Algorithms. Detroit, MI: Wayne State University Detroit.

Qi, K., Wang, Y., Wang, R., Wu, D., and Li, G.D. (2016). Facile synthesis of homogeneous CuInS2 quantum dots with tunable near-infrared emission. J. Mater. Chem. C. 4, 1895-1899. doi: 10.1039/C5TC04232A

Russell, J. T. (2011). Imaging calcium signals in vivo: a powerful tool in physiology and pharmacology. Br. J. Pharmacol. 163, 1605-1625. doi: $10.1111 / j .1476-5381.2010 .00988 . x$

SantaLucia, J. (1998). A unified view of polymer, dumbbell, and oligonucleotide DNA nearest-neighbor thermodynamics. Proc. Natl. Acad. Sci. U.S.A. 95, 1460-1465. doi: 10.1073/pnas.95.4.1460

Schefer, U., Ammann, D., Pretsch, E., Oesch, U., and Simon, W. (1986). Neutral carrier based $\mathrm{Ca}^{2+}$-selective electrode with detection limit in the sub-nanomolar range. Anal. Chem. 58, 2282-2285. doi: 10.1021/ac00124a036

Shu, G. W., Chiu, C. H., Huang, L. T., Lin, T. N., Yang, C. C., Wang, J. S., et al. (2013). Efficient energy transfer from InGaN quantum wells to Ag nanoparticles. Phys. Chem. Chem. Phys. 15, 3618-3362. doi: $10.1039 / \mathrm{c} 3 \mathrm{cp} 43894 \mathrm{e}$

Singh, A. K., and Mehtab, S. (2007). Calcium (II) -selective potentiometric sensor based on-furildioxime as neutral carrier, Sensor. Actuat. B-Chem. 123, 429-436. doi: 10.1016/j.snb.2006.09.016

Song, C., Haoyue, L., Xiaogang, L., Zhijia, P., Lingdong, W., Xiaosheng, T., et al. (2020). Study on AgInZnS-graphene oxide non-toxic quantum dots for biomedical sensing. Front. Chem. 8:331. doi: 10.3389/fchem.2020.00331

Suzuki, K., Tohda, K., Tanda, Y., Ohzora, H., Nishihama, S., and Inoue, H. (1989). Fiber-optic magnesium and calcium ion sensor based. Anal. Chem. 384, 382-384. doi: 10.1021/ac00179a018

Wegner, K. D., Dussert, F., Truffier-Boutry, D., Benayad, A., Beal, D., Mattera, L., et al. (2019). Influence of the core/shell structure of indium phosphide based quantum dots on their photostability and cytotoxicity. Front. Chem. 7:466. doi: $10.3389 /$ fchem.2019.00466

Wojda, U., Salinska, E., and Kuznicki, J. (2008). Calcium ions in neuronal degeneration. Critical Rev. 60, 575-590. doi: 10.1002/iub.91

Wu, T.-C., Biswas, S., Dutta, M., and Stroscio, M. A. (2011). Quantumdot-based aptamer beacon for the detection of potassium ions. IEEE Trans. Nanotechnol. 10, 991-995. doi: 10.1109/TNANO.2010. 2091967

Wu, M., Meng, S., Wang, Q., Si, W., Huang, W., and Dong, X. (2015). Nickel - cobalt oxide decorated three-dimensional graphene as an enzyme mimic for glucose and calcium detection. ACS Appl. Mater. Interfaces. 7, 3-8. doi: 10.1021/acsami.5b06299

Yun, C. S., Javier, A., Jennings, T., Fisher, M., Hira, S., Peterson, S., et al. (2005). Nanometal surface energy transfer in optical rulers, breaking the FRET barrier. J. Am. Chem. Soc. 127, 3115-3119. doi: 10.1021/ja04 $3940 \mathrm{i}$

Zuker, M. (2003). Mfold web server for nucleic acid folding and hybridization prediction. Nucleic Acids Res. 31, 3406-3415. doi: 10.1093/nar/ gkg595

Conflict of Interest: The authors declare that the research was conducted in the absence of any commercial or financial relationships that could be construed as a potential conflict of interest.

Copyright (๑) 2020 Ghosh, Chen, George, Dutta and Stroscio. This is an open-access article distributed under the terms of the Creative Commons Attribution License (CC $B Y)$. The use, distribution or reproduction in other forums is permitted, provided the original author(s) and the copyright owner(s) are credited and that the original publication in this journal is cited, in accordance with accepted academic practice. No use, distribution or reproduction is permitted which does not comply with these terms. 